\title{
Ski Yurt: Upcycle of Downhill Skis for a Shelter in Cacine-Guinea-Bissau
}

\author{
Graziano Salvalai, Marco Imperadori, Marta M. Sesana \\ and Gianluca Crippa
}

\begin{abstract}
Downhill skis are composite materials with very high performances. Very often after few years of use, they are changed due to new fashions or ski techniques. This means a lot of waste which still has the potential for very high structural performances. Thus, the idea to upcycle these materials thanks to a cooperation with the University of Grenoble in the joint activities of their laboratory and Velux Lab. Several tests and dome structures were realized in order to show the potential of these materials. Then a yurt was designed, tested, and pre-built at the Politecnico di Milano before shipping it to Africa, through the equatorial forest in Guinea-Bissau, as a first shelter-base camp in a desolated land where a mission was later founded. The purpose is also to make a structure with very high performances and that is resistant to the aggression of termites (only hard wood is suitable there but it requires deforestation) without using steel since it is too expensive. So the final goal is not to send waste to Africa but to show how waste can also become a very solid structure and a valued asset.
\end{abstract}

Keywords Shelter architecture $\cdot$ Skis $\cdot$ Upcycling $\cdot$ Recycling

\section{Introduction}

Skiing is one of the most popular sports in the world. According to recent estimates, about one hundred million people ski regularly or occasionally. Out of the European countries, Germany has the most people skiing by far with roughly 14.6 million participating in the sport, followed by France with approximately 8.5 million and the United Kingdom with 6.3 million (www.statista.com). The main equipment consists

G. Salvalai · M. Imperadori $(\varangle)$

Architecture, Built Environment and Construction Engineering-ABC Department, Politecnico di Milano, Milan, Italy

e-mail: marco.imperadori@polimi.it

M. M. Sesana

Polo Territoriale di Lecco, Lecco, Italy

G. Crippa

Lecco, Italy

(C) The Author(s) 2020

N. Aste et al. (eds.), Innovative Models for Sustainable Development in Emerging African

Countries, Research for Development, https://doi.org/10.1007/978-3-030-33323-2_7 
on skis which, after a number of seasons tend to be disposed of because of delamination, splinters, cracks, etc., or simply because they have become obsolescent. The skis are in general constructed from high-tech materials made up by a sequence of several layers: steel plates, plastics, and resins that gives high resistance and good ductility. The material composition of the skis is particularly complex and they cannot be recycled easily by deconstruction: the making-up materials of a typical alpine ski are assembled with a sandwich structure, perfectly bonded together and hard to disassemble. An alpine ski weighs about $1.8 \mathrm{~kg}, 35 \%$ of which is represented by the angular steel blades, $20 \%$ by the wood core, $10 \%$ by the surface foil, and the remaining part (about 35\%) is mostly represented by adhesives, foams, and rubber elements (Wimmer and Ostad-Ahmad-Ghoradi 2007). Regarding its disposal, the only recycled component is represented by the metal layer, while the remains are shredded and burned in incinerators contributing to the $\mathrm{CO}_{2}$ emission. Considering the cradle to grave approach (manufacturing, distribution, use, and disposal) and the approximately 1.500 tons of skis fallen into disuse every year, ski manufacturing absorbs a substantial amount of energy. The number of most ski areas in Europe can be found in Germany, with a total of 498. There are 349 ski locations in Italy, 325 in France, and 321 in Russia. The statistics shows a large number of skis sold every year: the number of alpine ski units sold in the USA from the 2015/2016 was close to 750,000. A survey carried out in five large ski areas in northern Italy, between March and April 2014, shows the amount of ski disposals (Table 1).

The interviews involved 23 ski shops with the aims to analyze the local ski's market trend, the technical life of the skis, and the amount of the equipment disposed of. From the data collected, about 2100 skis, approximately three tons of hightech material have been disposed of only during the winter season of 2014. In this scenario, supported also by the environmental impact analysis, reuse at the end of their life span represents an interesting opportunity. Furthermore, considering the high-performance characteristic concerning both the geometrical and the structural resistance, skis can be efficiently used as structural components in emergency shelter design. Several scientific studies concerning emergency post disaster shelters are available in literature dealing with the technological design, the adaptability, and

Table 1 Analysis of ski disposal in Lombardy (Italy)

\begin{tabular}{l|l|c}
\hline Place (Province) & $\begin{array}{l}\text { Number of ski's } \\
\text { shop interview }\end{array}$ & $\begin{array}{l}\text { Skis disposed per } \\
\text { year }\end{array}$ \\
\hline Livigno (SO) & 2 & 900 \\
\hline Bormio (SO) & 1 & 300 \\
\hline $\begin{array}{l}\text { Ponte di Legno } \\
\text { (BS) }\end{array}$ & 3 & 200 \\
\hline Madesimo (SO) & 2 & 200 \\
\hline Valle Seriana (BG) & 15 & 500 \\
\hline Total & - & 2100 \\
\hline
\end{tabular}

Source Surveys carried out by the authors between March and April 2014 
versatility of different solutions (Alegria Mira et al. 2014; Crawford et al. 2005; Battilana 2001; Meinhold 2014). Only few publications have focused on the reuse of recycled materials for shelter construction (Imperadori et al. 2014; Salvalai et al. 2017). The purpose of this work is to investigate the reuse of high-tech recycled materials for emergency and temporary architecture exploiting the characteristic of high technology (Daudon 2015; Jalesse et al. 2015). A temporary emergency shelter called "Ski Shelter" composed of recycled skis and covered in a lightweight envelope composed of thermal-reflective-multilayer insulation and polyvinyl chloride (PVC) sheet, has been studied, and built in real scale. The joint between skis has been tested, from the structural point of view, with experimental tests. The first tent prototype has been donated to the Missionaries Oblates of Mary Immaculate and is now operating in the Republic of Guinea-Bissau.

\section{The Ski Shelter: Concept and Technology}

The Ski Shelter project aims to develop a shelter prototype characterized by an easy assembly method, lightweight, and reused materials, with the capacity to maintain acceptable internal thermal comfort conditions for the user in hot and cold temperatures.

The basic design began from the archetype of the Mongolian yurt, represented by a portable, round tent covered with skins or felt and used as a dwelling by several distinct nomadic groups in the steppes of Central Asia (Fig. 1). The ski yurt prototype has been designed as a composition of a regular grid made up of: 24 concentric axes, representing the beams, and 24 pillars, which together divide the circular base. At the center of the room, a pillar composed of reused standard steel elements for building scaffolding supports the openable $80.0 \times 80.0 \mathrm{~cm}$ skylight. Linear assembly of several skis constitutes the beams and pillars, the tips of each ski have been previously modified, according to the structural design. The skis have been assembled together to create composite beams and pillars, increasing the inertia and stability, locally and globally. The joints between skis were reinforced with wooden spacer elements (Fig. 2).

The designed geometry has a diameter of $6.0 \mathrm{~m}$, which covers an area of approximately $30.0 \mathrm{~m}^{2}$ (Fig. 3). The internal height is equal to $1.70 \mathrm{~m}$ at the lowest point and $3.80 \mathrm{~m}$ in the center of the building area. The shelter is modular and the number of units is potentially implementable according to the emergency situation requirements: the coupling of multiple Ski Yurts allows for a variation of the spaces reaching variable housing dimensions. The building envelope has been created from a textile material coupled with different resistive layers: a double PVC layer, both outside and inside, with a thermo-reflective insulation system interposed in between (Fig. 4).

The high of the pitched roof has been increased in order to maximize the "chimney effect" and improve consequently thermal comfort during summer (Fig. 5). The Ski Yurt prototype can be used as a single shelter or can be assembled into a more complex architecture by means of a modular connection space. 


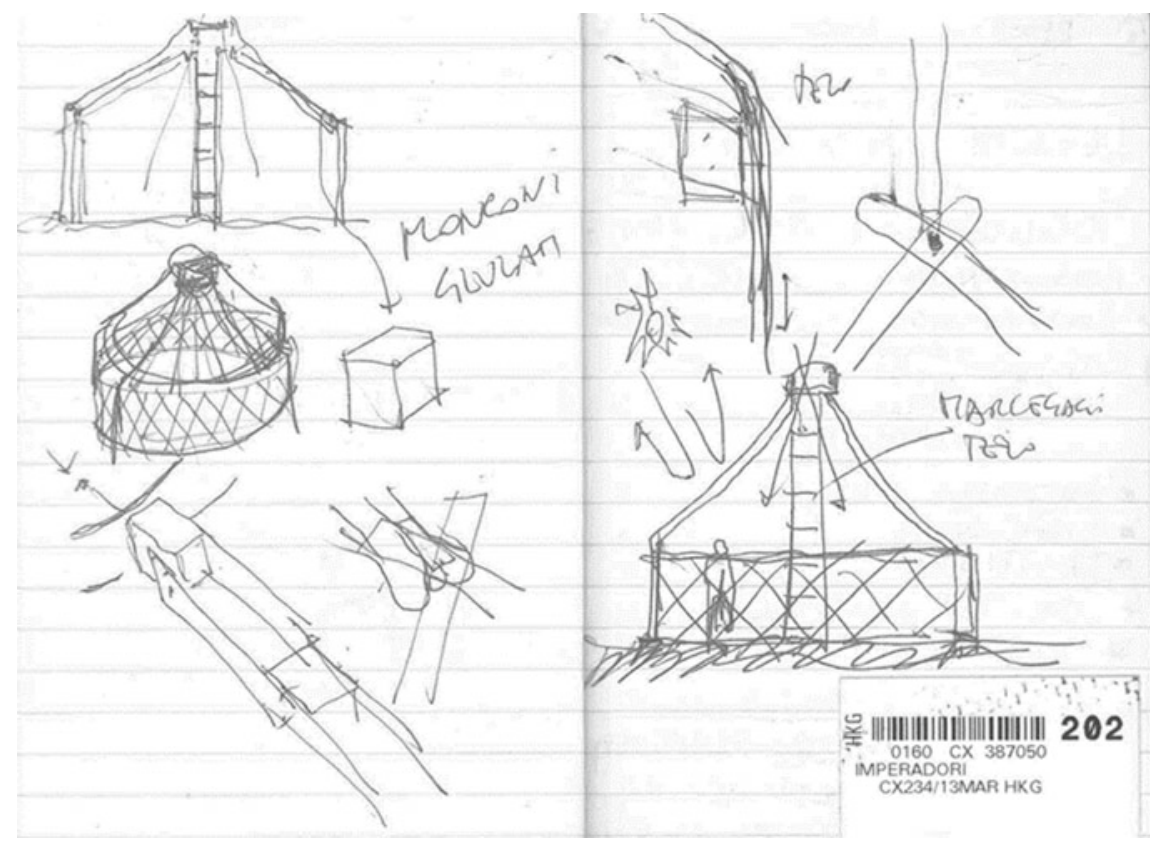

Fig. 1 Schematic concept of the ski yurt. Source Marco Imperadori
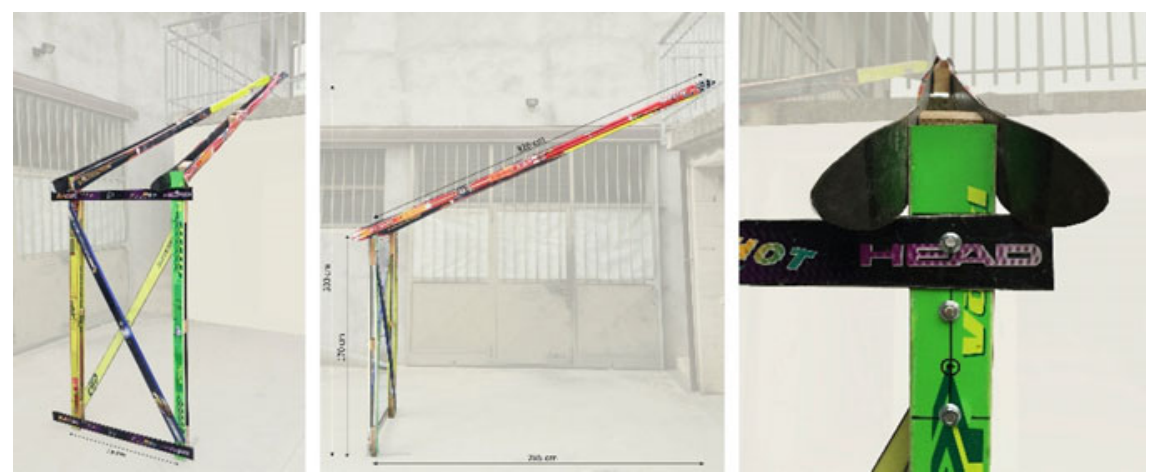

Fig. 2 Photorealistic view of a structure module

\subsection{Technological Design}

In order to make shelters easy to erect and dismantle, they need to be light weight and have few and easy assembled pieces. Certain types of shelters, such as plastic sheets and tents, are simply erected for a short time span and then dismantled. If the design of a shelter is complex, it will require more training and resources to build it, leading to potential delays (Bashawri et al. 2014). The solutions adopted for the 


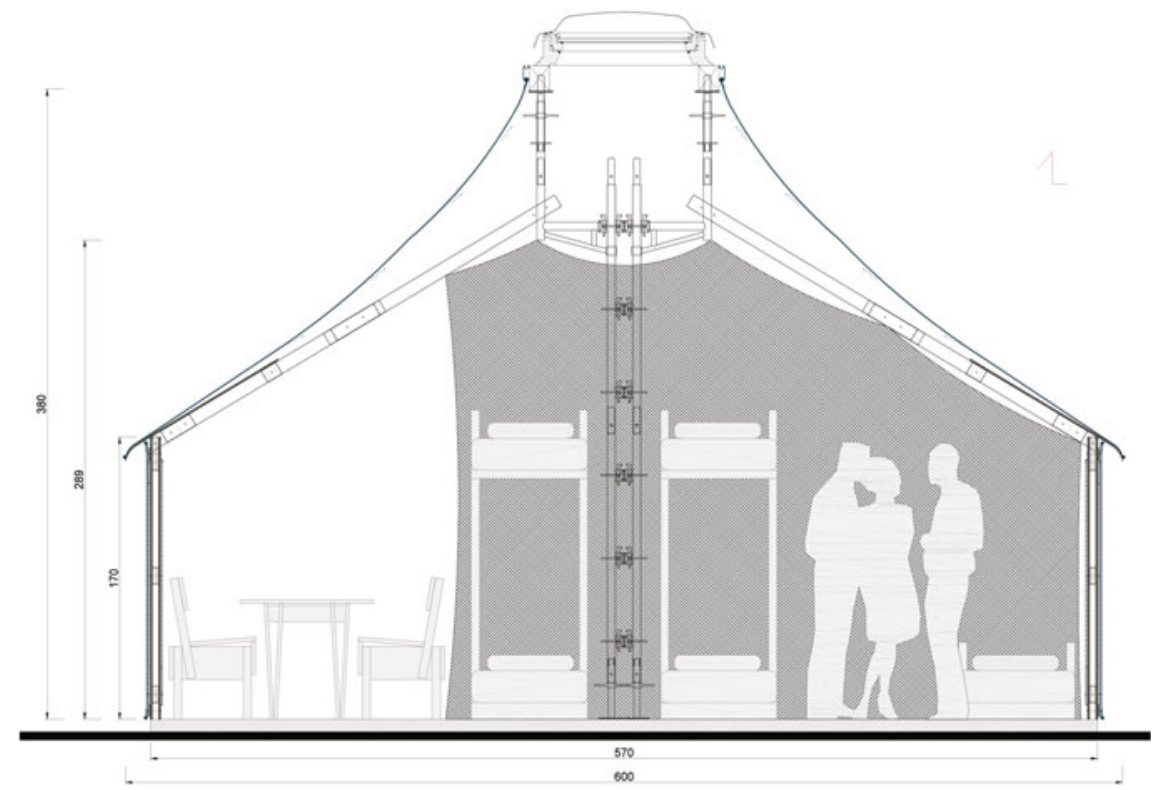

Fig. 3 Vertical section of a standard Ski Shelter

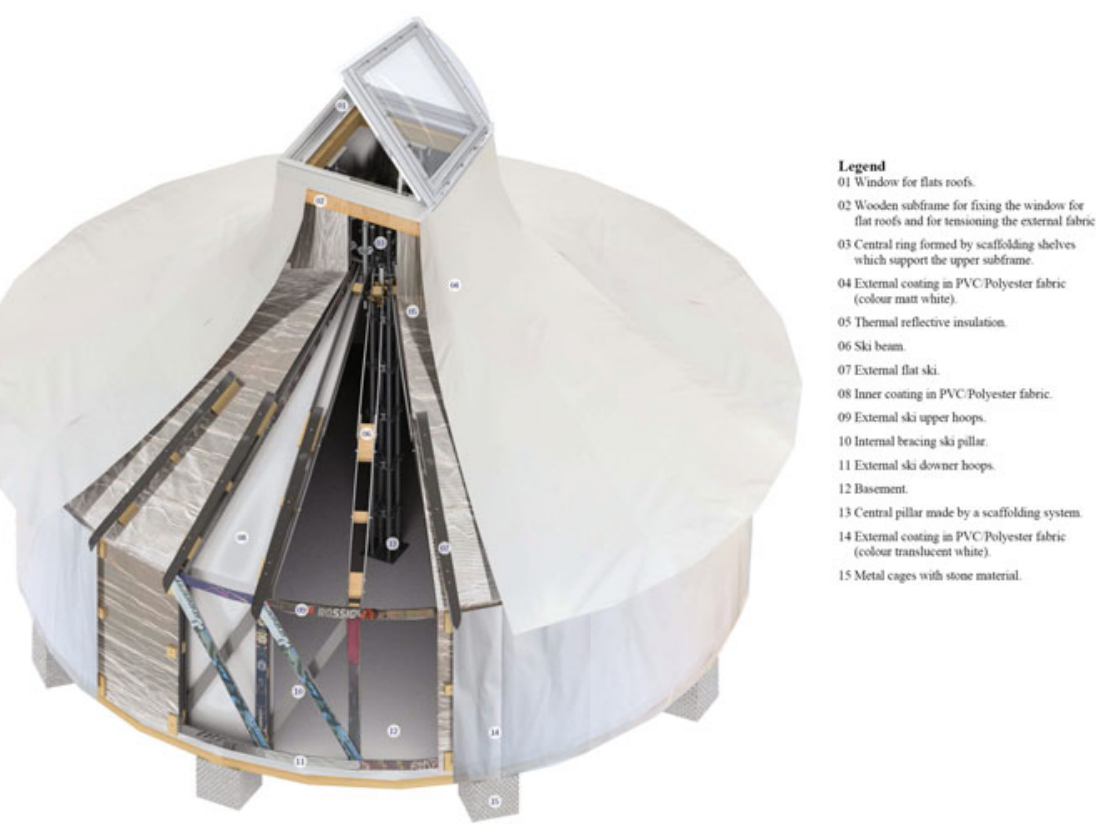

Fig. 4 Photorealistic view of the Ski Shelter 
(a)

Winter operation

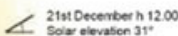

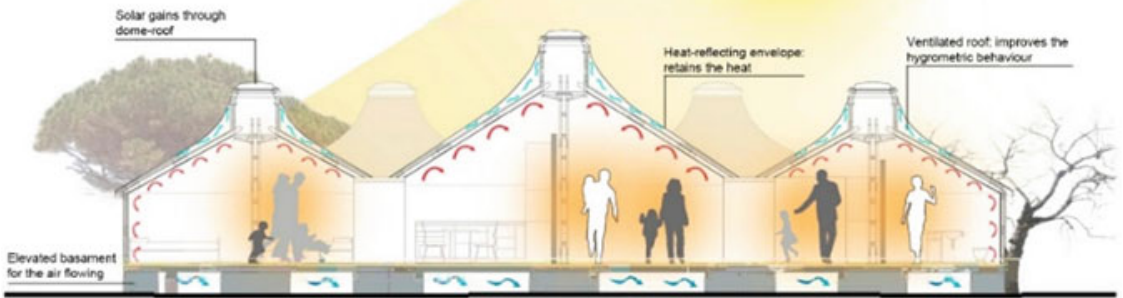

(b)

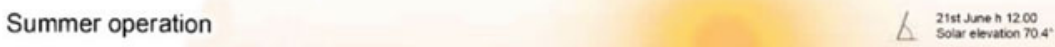

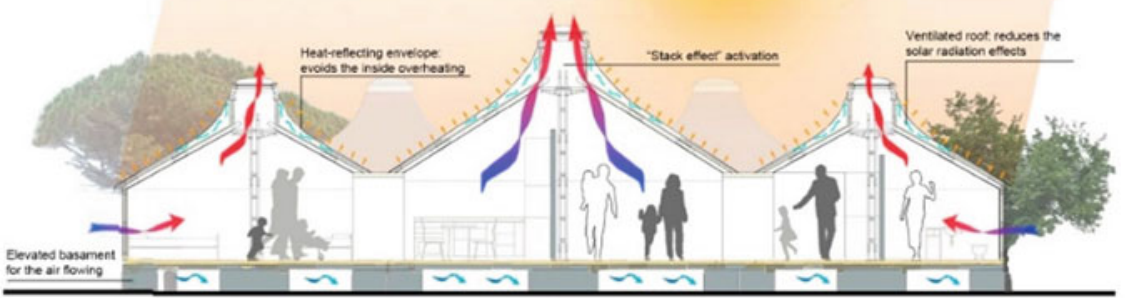

Fig. 5 a Winter and $\mathbf{b}$ summer schematic design of the Ski Shelter

Ski Shelter assembly do not require special skills or in situ operations, and respect the requirements typical of the emergency structure, such as flexibility, portability, lightness, quick installation process, and durability. Considering that the external layer has been made up from a polyester/PVC material, which is characterized by a translucency range of about $0.8-4.0 \%$ and with high resistance (Fig. 6). This material presents effective fire resistance and a low specific weight $\left(1450.0 \mathrm{~g} / \mathrm{m}^{2}\right)$. Currently, polyester/PVC is the material most commonly used in architecture since it provides a good balance between cost, performance, and durability (the average life span is between 7 and 15 years), strength and elasticity (Campioli and Zanelli 2009). The thermal resistance to heat transfer is given by the presence of the reflective multilayer insulation (MLI), material already tested by different research studies (Imperadori et al. 2013; Ward and Doran 2005; Salvalai et al. 2015).

This material is a thermal insulation composed of multiple layers of thin sheets developed mainly for spacecrafts. It is commonly used on satellites and other applications in a vacuum where conduction and convection are much less significant, and radiation dominates. In general, the material consists of a series of reflective films covered in a material with low emissivity such as aluminum films and reflective plastic films. For about 30 years, these materials have been used in building, where they 

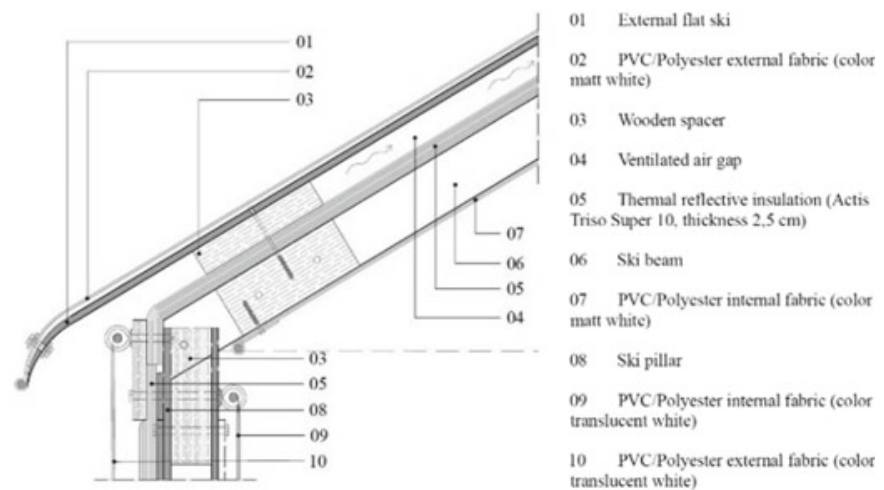

$01 \quad$ PVC/Polyester extemal fabric (color translucent white)
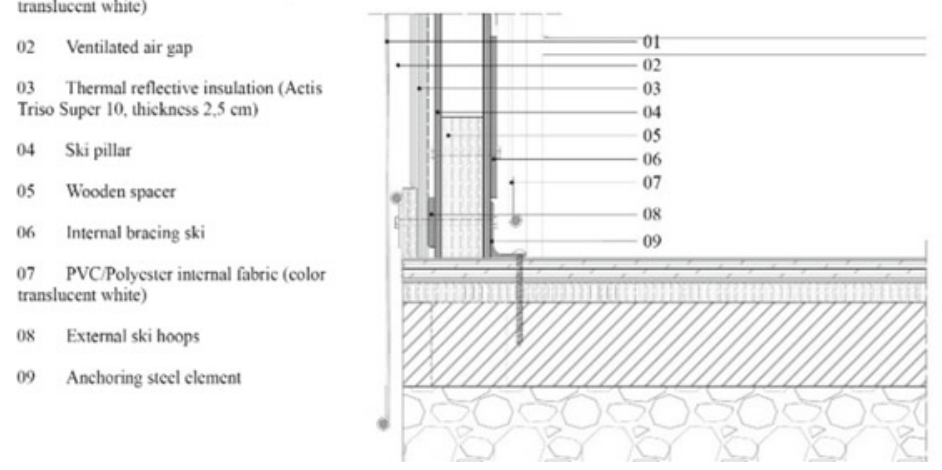

Fig. 6 Constructive detail of the connection Ski Shelter

are able to effectively solve, and in an innovative manner, the problem of thermal insulation, acting in all heat transfer directions. The MLI used in the present study is the ACTIS TRISO Super 10 multilayer (http://www.actis-isolation.com). It is composed of synthetic materials such as wadding sheets or plastic material; and natural fibers, such as sheep's wool. The combination of these thin materials, arranged in succession to one another, gives excellent results in terms of thermal performances: in winter months, it prevents the heat flow from the inside to the outside, while in summer months, when the radiative component of the external thermal load is bigger than the conductive and convective one, it reduces the heat flow from the outside. Figure 6 shows the technological details of the Ski Shelter: the connection between the ground and the skis and between the vertical wall and the roof structure. 


\subsection{Concept Design and Testing Procedure}

The Ski Yurt geometry offers exceptional mechanical resistance being composed of several structural elements close to each other. As mentioned before, the Yurt is built on the basis of 24 concentric triangles with a rotation of $15^{\circ}$. In the center of the Yurt a steel pillar sustains the "crown" which acts as a support for the roof window and the other structural elements that converge on it. To each axis corresponds a composite "ski beam" tilted $30^{\circ}$ on the horizontal plane, which is anchored to the "crown" at the top and to the "ski pillar edge" at the bottom (Fig. 7). At both points, the joint does not neither transfer shearing actions nor bending moment (hinge behavior). Different diagonal skis contribute to withstanding the horizontal forces. In the end, the horizontal stress coming from the beams is absorbed by two orders of "ski hoops" placed one on the top and one on at the base of the pillars' edge. Again, these joints are discretized as three-dimensional hinges. All the nodes of the structure have been connected by threaded steel bolts.

In 2015, together with the Politecnico di Milano and ESPE Lecco (a technical professional school for construction workers in Lecco), the Ski Yurt was tested verifying the construction phases. The main goal was to derive specification and suggestion for further design and construction optimization. During the test, all the technical elements have been numerically named to help and speed up the assembly phase (Fig. 8).
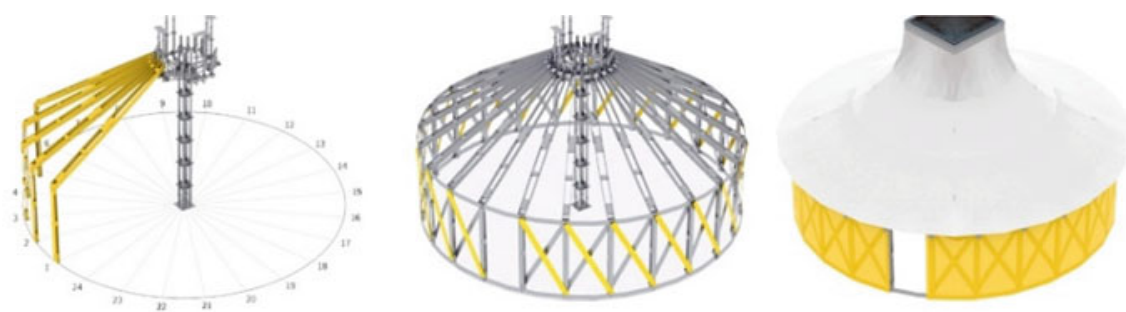

Fig. 7 Technical drawing of the different construction phases
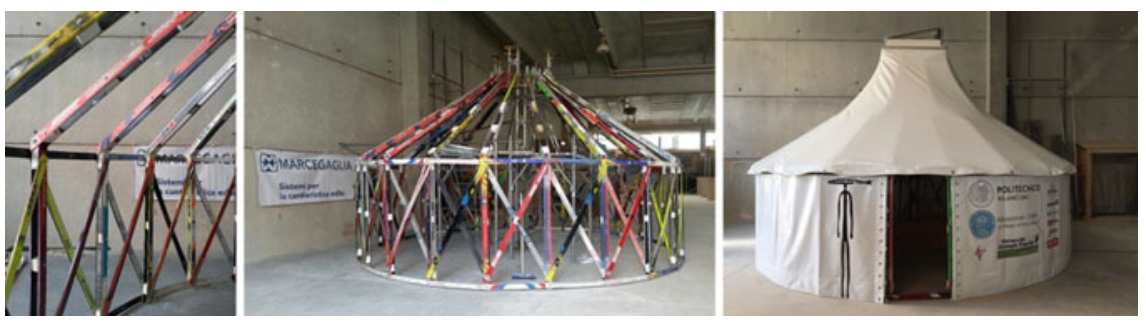

Fig. 8 Pictures of the pre-assembly phase 
The whole construction process took four working days to assemble the skis for the individual structural elements, such as beams and pillars. Then, it took an additional five days to assemble the whole yurt structure. The working team was composed of an average of four people, two of them skilled workers and two of them students. The shelter was then taken apart in half a day, packed and loaded into a container ready for shipping to Guinea-Bissau.

\section{Performance Verification: Simulation Study}

Several studies are available in literature analyzing the shelter performances through experimental and simulation studies in different geographic areas that verify the internal conditions (Cornaro et al. 2015; Ajam 1998; Manfield 1999, 2000). The tent prototype was also analyzed by dynamic thermal analyses performed with Trnsys v.17 Environment (https://sel.me.wisc.edu/trnsys/). The geometrical model (Fig. 9) was modeled in Trnsys3d (http://www.trnsys.de/), a plug-in for Google SketchUp.

The geometry was modeled as a homogenous thermal zone with a total volume of $83.15 \mathrm{~m}^{3}$. The vertical surface $\left(33.84 \mathrm{~m}^{2}\right)$ and pitched roof $\left(43.15 \mathrm{~m}^{2}\right)$ have been implemented in type 56 considering a solar absorbance coefficient of 0.4 (clear color) and the convective heat transfer coefficients were set equal to $3.0 \mathrm{~W} /\left(\mathrm{m}^{2}{ }^{\circ} \mathrm{C}\right)$ for internal surfaces and $17.8 \mathrm{~W} /\left(\mathrm{m}^{2}{ }^{\circ} \mathrm{C}\right)$ for the external ones. The ground floor was modeled considering the direct contact between the ground and the internal zone. The model allows for predicting the internal temperature considering in one side the free-running operation and in the other side the ideal heating/cooling demand with an internal set point control of $18^{\circ} \mathrm{C}$ in winter and $26^{\circ} \mathrm{C}$ in summer. The simulation was performed considering the climate of Palermo (Italy), characterized by high ambient air temperature in the summer with high solar heat gains. The thermal performance of the tent is summarized in the Table 2.

Different ventilation strategies have been tested: night-time ventilation (8:00 p.m. to 8:00 a.m.) and day-time ventilation (10:00 a.m. 14:00 p.m.) both with an air change of 3 volumes per hour (ach). Changing from day ventilation to night ventilation there is no significant reduction of the temperature level due to the low thermal inertia of the yurt envelope. In general, intensive ventilation strategies allow for an increase in the

Fig. 9 Three-dimensional single thermal zone simulation model
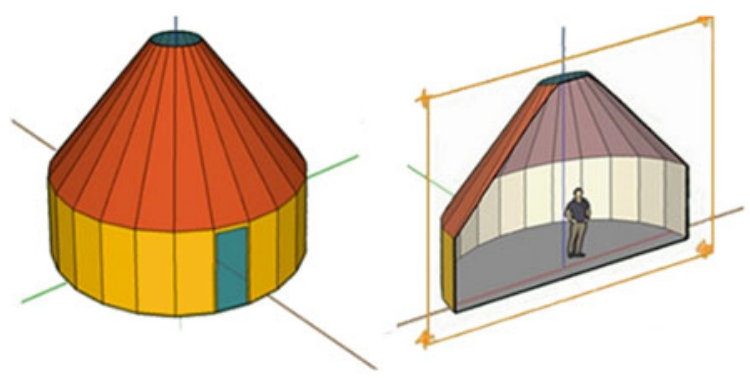
Table 2 Features of the elements that make up the multilayer technology

\begin{tabular}{|c|c|c|}
\hline & Thickness (mm) & $\mathrm{R}\left(\mathrm{m}^{2} \mathrm{~K} / \mathrm{W}\right)$ \\
\hline \multicolumn{3}{|l|}{ Wall/roof $\left(R_{\mathrm{tot}}=5.538 \mathrm{~m}^{2} \mathrm{~K} / \mathrm{W}\right)$} \\
\hline$R_{\mathrm{Si}}$ & & 0.131 \\
\hline Internal envelope in Polyester/Pvc & 1.20 & 0.006 \\
\hline Air gap & 60 & 0.182 \\
\hline Insulation ACTIS TRISO SUPER 10 & 25 & 5 \\
\hline External envelope in Polyester/Pvc & 30 & 0.176 \\
\hline$R_{\mathrm{se}}$ & & 0.038 \\
\hline \multicolumn{3}{|l|}{ Basement $\left(R_{\mathrm{tot}}=3.768 \mathrm{~m}^{2} \mathrm{~K} / \mathrm{W}\right)$} \\
\hline$R_{\mathrm{si}}$ & & 0.171 \\
\hline Internal envelope in Polyester/Pvc & 1.20 & 0.006 \\
\hline Background slab & 25 & 0.834 \\
\hline Insulation ACTIS TRISO SOLS & 7 & 2.5 \\
\hline OSB panel & 28 & 0.215 \\
\hline$R_{\mathrm{se}}$ & & 0.038 \\
\hline
\end{tabular}

interior comfort conditions. The thermal comfort level has been analyzed according to the EN UNI 15251:2008 standard. Figure 10 shows the correlation between the operative room temperature (ORT) and the running mean ambient air temperature.

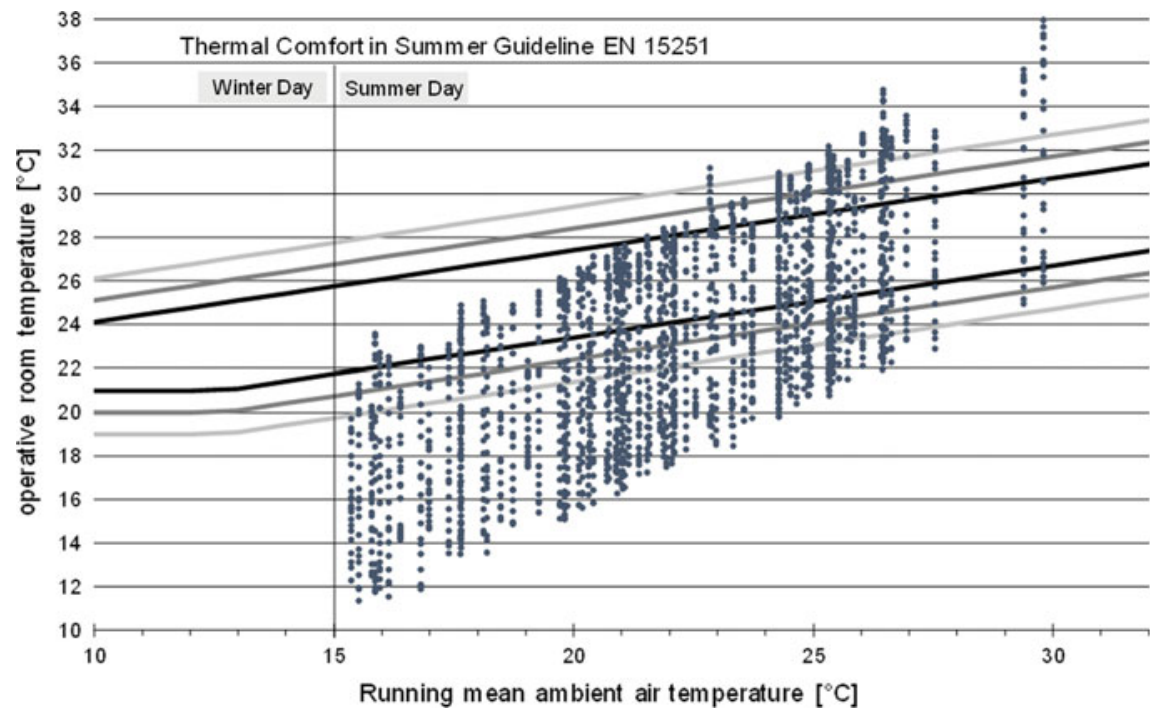

Fig. 10 Summer thermal comfort evaluation according to the EN 15251 standard 

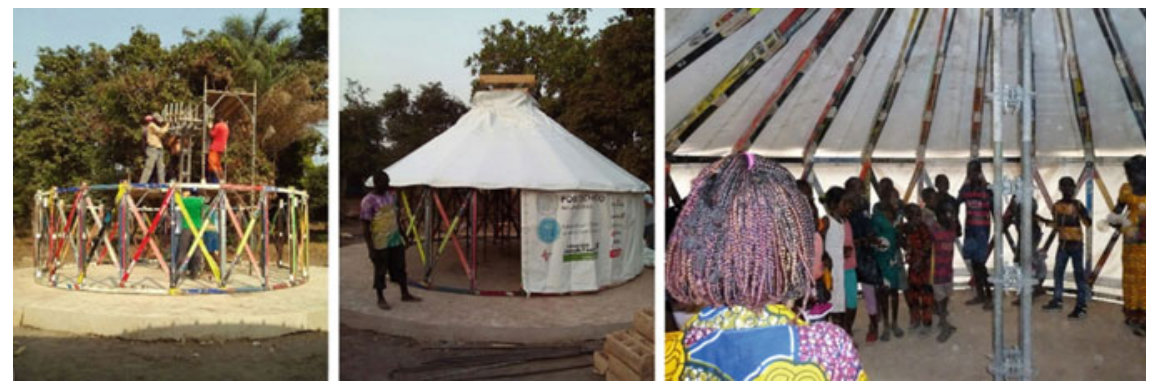

Fig. 11 Construction phases in Cacine, Guinea-Bissau

The annual energy balance (useful energy) shows that the cooling consumption exceeds that for heating at about twice the amount: the energy for cooling is equal to $1003 \mathrm{kWh}$ and those for heating equal to $559 \mathrm{kWh}$. The total energy related to the floor area is equal, respectively, to $33.3 \mathrm{kWh} / \mathrm{m}^{2} \mathrm{y}$ and $18.6 \mathrm{kWh} / \mathrm{m}^{2} \mathrm{y}$, reflecting the predominant summer climate conditions of southern Italy. The low energyconsumption level would lead to different benefits such as energy procurement and fuel transportation.

\section{Conclusion and Development}

The presented work demonstrates the high potential of upcycle materials like disposed of skis, in order to use them for building temporary and emergency architectures, due to their features of lightness, quick installation, and flexibility.

The Ski Yurt shows an innovative concept of potential living, a secure, comfortable, and healthy space easily assembled and disassembled. Modularity and simple connections between different components guarantee easy transport, assembly, and maintenance by locals without specific tools and skills. The experimental Ski Yurt, after the assembly test in Italy, has been donated and transported to the Cacine community to become the base camp for the new mission center coordinated by the Oblate Fathers of Mary Immaculate (Fig. 11). Local people rebuilt the Ski Yurt easily, and since then it has become an important reference point for the population as a useful, comfortable, and safe space.

Acknowledgements The presented work has been carried out on the basis of the content of the master thesis entitled: ARCA project. Architecture of resilience and community accommodation. Android —resilience shelter: strutture temporanee per l'emergenza abitativa, resilienti e ad elevate prestazioni termodinamiche (authors: Federico Lumina, Elisa Mutti, Ilaria Polese). The authors would like to thank the students for the amazing work and for the effort in making possible the construction of the Ski Yurt prototype. The authors would like to thank all the industrial partners who provided materials and expertise: Velux, Cittadini, SergeFerrarì, Canobbio, Marcegaglia, Joseph Fourier University. 


\section{References}

Ajam R (1998) Thermal comfort in low-cost refugee shelters: a computer simulation study in Waqas, a lower desert valley area in Jordan. UNRWA-HQ, Amman

Alegria Mira L, Thrall AP, De Temmerman N (2014) Deployable scissor arch for transitional shelters. Autom Constr 43:123-131

Bashawri A, Garrity S, Moodley K (2014) An overview of the design of disaster relief shelters. Proc Econ Finance 18:924-931

Battilana R (2001) Design of cold climate temporary shelter for refugees. University of Cambridge. Master thesis. Source: www.shelterproject.org/downloads/cold\%20climate\%20liner.pdf

Campioli A, Zanelli A (2009) Architettura tessile. Progettare e costruire membrane e scocche, Il Sole 24 Ore, Milano

Cornaro C, Sapori D, Bucci F, Pierro M, Giammanco C (2015) Thermal performance analysis of an emergency shelter using dynamic building simulation. Energy Build 88:122-134

Crawford C, Manfield P, McRobie A (2005) Assessing the thermal performance of an emergency shelter system. Energy Build 37:471-483

Daudon D (2015) Innovation and sustainable development in civil engineering degrees: constructing structures with re-used skis. Université Joseph Fourier, Grenoble

Imperadori M, Pusceddu C, Salvalai G (2013) Thermal-reflective multilayer insulation systems in the emergency architecture: the Air Shelter Skin, Plea Conference 2013. Munich, Germany

Imperadori M, Salvalai G, Pusceddu C (2014) Air shelter house technology and its application to shelter units: the case of scaffold house and cardboard shelter installations. Procedia Econ Finan 18:552-559

Jalesse K, Wauthy R, Diagne A (2015) Innovation et Développement Durable dans les formations GC: conception collaborative et normative pour l'habitat d'urgence, réalisation d'une yurte en skis usages. Joseph Fourier University, Grenoble

Manfield P (1999) A comparative study of temporary shelters used in cold climates. Martin Centre

Manfield P (2000) Modelling of a cold climate emergency shelter: prototype and comparison with the United Nations Winter Tent. Martin Centre, Cambridge

Meinhold B (2014) Urgent architecture: 40 sustainable housing solutions for a changing world. W. W. Norton \& Company, Inc

Salvalai G, Imperadori M, Scaccabarozzi D, Pusceddu C (2015) Thermal performance measurement and application of a multilayer insulator for emergency architecture. Appl Therm Eng 82:110-119

Salvalai G, Imperadori M, Lumina F, Mutti E, Polese I (2017) Architecture for refugees, resilience shelter project: a case study using recycled skis. Procedia Eng 180:1110-1120

Skiing in Europe-Statistics \& Facts, https://www.statista.com/topics/3922/skiing-in-europe/

Thermal reflective insulation materials. Source: http://www.actis-isolation.com

UNI EN 15251:2008 Criteri per la progettazione dell'ambiente interno e per la valutazione della prestazione energetica degli edifici

Ward TI, Doran SM (2005) Thermal performance of multi-foil insulation, Report BRE, Scotland, Glasgow. Source: www.planningportal.gov.uk/uploads/br/multi-foil-insulation_july2005.pdf

Wimmer W, Ostad-Ahmad-Ghoradi H (2007) Ecodesign of Alpine skis and other sport equipmentconsidering environmental issues in product design and development. The Impact of Technology on Sport II, Taylor \& Francis Group, pp 15-23 
Open Access This chapter is licensed under the terms of the Creative Commons Attribution 4.0 International License (http://creativecommons.org/licenses/by/4.0/), which permits use, sharing, adaptation, distribution and reproduction in any medium or format, as long as you give appropriate credit to the original author(s) and the source, provide a link to the Creative Commons license and indicate if changes were made.

The images or other third party material in this chapter are included in the chapter's Creative Commons license, unless indicated otherwise in a credit line to the material. If material is not included in the chapter's Creative Commons license and your intended use is not permitted by statutory regulation or exceeds the permitted use, you will need to obtain permission directly from the copyright holder.

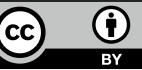

